\title{
EL DESTINO DE HÖLDERLIN
}

\author{
HÖLDERLIN'S FATE
}

David Mayor

Helena Cortés Gabaudan, La vida en verso. Biografía poética de Friedrich Hölderlin, Madrid: Hiperión, 2015.

I.

Helena Cortés Gabaudan, traductora de Goethe, Schelling, Heidegger o Adorno, es, sobre todo, una especialista en Hölderlin. En 1996, publicó el estudio Claves para una lectura de Hiperión. Filosofía, política, ética y estética en Hölderlin. Pero es en 2015 con La vida en verso. Biografía poética de Friedrich Hölderlin, publicado, como el anterior volumen, por la editorial Hiperión de Madrid — que con empeño y tino cuida y traduce al castellano desde hace más de treinta años el legado de un poeta que siempre será leído_- cuando Cortés Gabaudan se ha revelado afín al poeta de Tubinga hasta el entusiasmo. Pero no encontramos debilidad hagiográfica en La vida en verso sino un texto riguroso que se pone detrás de la figura del poeta y recorre los pasos y las preguntas holderlinianas con apasionada vocación hermenéutica, con sinceridad pero sin adoración y apartada en su intención de cualquier tipo de lectura marcadamente ideológica, patrañas las llama (Cortés Gabaudan 2015, p. 430).

La vida en verso se lee con avidez e interés tanto literario como filosófico; la autora ha sabido concitar el acercamiento a una personalidad poliédrica y sin fin con el rigor de un tratamiento que lo inscribe en unas determinantes circunstancias históricas: la aurora de un tiempo nuevo impulsado por la Ilustración y la Revolución francesa que adquirirá tensión extrema con el Romanticismo. No obstante, en esta biografía, articulada como construcción de la respuesta a la aparentemente fácil pregunta ¿Quién es Hölderlin?, relato de un yo al que se mira desde la distancia del tiempo, las circunstancias históricas son sólo telón de fondo para la compresión e interpretación de la historia del sujeto Hölderlin. No tienen un papel parangonable a la peripecia del poeta y a la construcción de su voz poética. Incluso la voz filosófica de Hölderlin queda en un segundo plano. Ni 
siquiera cobra protagonismo principal la tensión entre lo poético y lo filosófico, ese correlato que, como decía María Zambrano, en los casos más afortunados, como el de Hölderlin, llega a trabarse en una sola forma expresiva (Zambrano 13). A pesar de ese simulado segundo plano, Helena Cortés muestra la singularidad de dicho vínculo en distintos pasajes de su biografía, por ejemplo en un delicioso diálogo a tres bandas entre Hegel, Schelling y Hölderlin en torno a la necesidad de una Nueva Iglesia de la Razón, contagiados por el espíritu revolucionario que recorría Tubinga en 1793 y que dará lugar al "Más antiguo programa de sistema del Idealismo alemán". La conversación es imaginada por la autora pero utiliza algunos significativos fragmentos del "Programa":

«el filósofo debe tener tanta fuerza estética como el poeta» [le dice Hölderlin a Schelling], pues la razón no vale nada sin un envoltorio estético que permita intuir de un modo inmediato y sin necesidad de complicadas operaciones lógicas sólo accesibles a los más ilustrados. Yo creo que nunca lograrás acercar las ideas racionales y filosóficas al pueblo si no van envueltas en una forma artística.

—Tú hablas así porque eres poeta —interrumpe Hegel— pero ¿de verdad crees que el arte o la poesía pueden tomar ese papel tan elevado?

—Eso creo, y si se hace así, entonces «la poesía recibe una más alta dignidad y vuelve a ser al final lo que era al principio: maestra de la humanidad, pues ya no hay filosofía, ya no hay historia, sólo la poesía sobrevivirá a todas las demás ciencias y artes».

(Cortés Gabaudan 2015, pp. 164-165).

Un todavía joven Hölderlin reivindica, pues, una filosofía que adquiera forma poética y una poesía que recupere la dignidad que tiene la filosofía. Poco después, 1795, parece que el interés principal del poeta se decanta por la filosofía. Tensión, decíamos. Asiduo en Jena a las clases de Fichte, por cuyo pensamiento sentirá especial debilidad, tal y como indican múltiples testimonios en sus cartas. Por ejemplo en una a su madre del 17 de noviembre de 1794: "la nueva filosofía de Fichte me absorbe completamente. Sus cursos son, por otra parte, los únicos a los que asisto". (Holderlin 1990a) Sin embargo, tal y como recoge Antonio Pau en Hölderlin. El rayo envuelto en canción, su acercamiento apasionado a Fichte y a la filosofía también decaerá. Escribe el propio Hölderlin:

«Me he dedicado con demasiada atención y esfuerzo a ocupaciones probablemente menos conformes con mi naturaleza, como la filosofía, por temor a ser considerado un poeta vacío. Durante mucho tiempo no he entendido por qué la filosofía, cuyo estudio asiduo encuentra su recompensa en el sosiego que produce, a mí me hacía 
cada vez más inquieto, e incluso más apasionado, a medida que me dedicaba a ella con más intensidad. Y ahora me lo explico: me estaba alejando más de lo razonable de mi vocación propia. Como consecuencia de un trabajo tan opuesto a su naturaleza, mi corazón sentía nostalgia de su ocupación favorita.»

(Pau 87)

La filosofía, "trabajo tan opuesto a su naturaleza", nos dice. La identidad holderliniana se presenta llena de una "ocupación favorita": la poesía. Insistencia de la tensión entre las dos disciplinas. Una dualidad que, por otra parte, no dejará nunca de ser especular.

Pero no es profusa la biografía de Helena Cortés en indagar en ese conflicto. Se entiende que existe y se constata porque el reflejo y la refracción entre poesía y filosofía es uno de los argumentos centrales de la peripecia personal de Hölderlin, es más: constituye uno de los límites que le definen. Pero no es La vida en verso un texto que aborde este asunto desde un punto de vista teórico. Otros son los textos que se adecúan. Para mostrar el relato de Hölderlin y la construcción de su destino, que defiende como abiertamente poético, Helena Cortés avanza por los acontecimientos personales. Nos cuenta a Hölderlin. Lo relata. No estamos ante otro tipo de libro. Al respecto la autora es muy sincera. Escribe en el prólogo:

«es demasiado el grado de complejidad de su pensamiento poético y filosófico como para pretender contarlo banalmente en una pocas páginas biográficas y, de querer explicarlo con la debida profundidad, sería casi inevitable caer en el tratado literario o en el ensayo filosófico [...] En nuestro caso, hemos tratado de encontrar un tono narrativo literario, que sin perder de vista la fidelidad al dato siempre contrastable que inspira cada uno de los elementos que aparecen [...], está más cercano a una evocación personal que al quehacer del puro cronista, y desde luego sin pretensión de exhaustividad. Según el tema tratado en cada capítulo el tono puede variar desde un discurso algo más cercano a la investigación filológica hasta otro más próximo a la pura ensoñación ficcional. La tesis de partida [...]: contar la vida de Hölderlin como destino poético.»

(Cortés Gabaudan 2015, p. 15)

Por lo tanto, dos son los puntos esenciales: contar la vida y desvelar lo poético. Y, obviamente, el recorrido se atiene a lo biográfico: la difícil relación filio-materna; los dichosos años del seminario; la amistad, truncada, con sus compañeros Hegel y Schelling, la fraternal con Neuffer y, especialmente importante en la biografía, con Sinclair; la frustrante posición en el mundo intelectual y académico del momento, el desprecio de Goethe, el olvido de Schiller; las dificultades para ganarse la 
vida; los viajes hacia ninguna parte, el viaje hacia sí mismo; el amor por Sussette Gontard; la reclusión psiquiátrica y el apartamiento del mundo en la torre del ebanista Zimmer al cuidado de su hija Lotte, cuando Hölderlin dejara de ser sólo Hölderlin para ser también Scardanelli, Buonarroti, Salvator Rosa, Kilalusimeno, sólo él supo quién más. Acontecimientos que Helena Cortés presenta con pulso narrativo y personal mirada, pero sin salir nunca del referente ensayístico. No se trata en absoluto — ella misma lo apunta - de un acercamiento novelesco similar al que hiciera Peter Härtling o teatral como el de Peter Weiss. Tampoco aborda la vida de Hölderlin con vocación arqueológica y perfil académico, como sería el caso de la biografía de Antonio Pau o el clásico estudio de Pierre Bertaux, de quien Cortés se aparta en temas esenciales como es el de la locura de Hölderlin.

La tesis de Bertaux es la de la pintada en dialecto suabo que adorna la torre junto al Neckar donde el poeta viviera recluido los últimos treinta y seis años de su vida: "Der Hölderlin isch et verrückt gwa", es decir, "Hölderlin no estaba loco". Opinión que no comparte Cortés, para quien la estrafalaria y marginal vida del segundo Hölderlin es suficiente para justificar su enfermedad como anomalía, patología psiquiátrica, locura sin más (Ib. 360-361). No considera en ningún momento que acaso fuera una decisión consciente con la que Hölderlin se apartaba de un mundo y de unas formas literarias que no le habían servido para alcanzar la verdad. Cuando decimos consciente, uno sabe lo atrevido de la expresión; no puede obviar que del viaje a Burdeos entre diciembre de 1801 y junio de 1802 - excelentemente narrado por Vicente Valero en El arte de la fuga- Hölderlin regresó enajenado y fuera de sí, y que muchos lo han planteado como un brote de esquizofrenia —Karl Jasper en Genio artístico y locura, por ejemplo- que se repetirá hasta su ingreso en el psiquiátrico de Tubinga contra su voluntad en septiembre de 1806, de donde saldrá en 1807, considerado incurable, tras sufrir dantescos tratamientos . A partir de ese momento, Hölderlin no volverá a ser quien era, será otro. Después de 1838 ni firmará con su nombre. "Yo, señor mío, ya no me llamo Hölderlin. Me llamo Scardanelli” (Pau 361).

Al decir que Hölderlin era consciente de que buscaba una cesura en su vida y en su obra, uno piensa en la carta que le envía a Böhlendorf, justo antes de emprender su viaje a pie hasta Francia, el 4 de diciembre de 1801 en la que escribe:

«lo más difícil es el libre uso de lo que nos es propio. [...] Pues lo que es trágico para nosotros es nuestra manera de abandonar dulcemente y para siempre el reino de los vivos y que no seamos consumidos por las llamas que no supimos apagar.

$\mathrm{Y}$ es verdad que el alma se conmueve tanto en una situación como en la otra. Éste es un destino menos deslumbrador, pero más profundo, y un alma bella se 
identifica con semejante moribundo, temerosa y piadosamente, elevando el espíritu gracias al furor.

[...] Deberé ser prudente para no perder la cabeza en Francia, en París. [...] El mundo es ahora más claro para mí y más grave.

¡Amigo mío! Antaño me regocijaba al encontrar una verdad nueva, una concepción más justa sobre lo que habita y está en torno a nosotros, pero ahora tengo miedo de sufrir finalmente la suerte de Tántalo, quien recibió de los dioses más de lo que podía soportar.»

(Hölderlin 1990b, p. 109)

Tántalo que ha alcanzado la verdad de los dioses y luego no quiere ser castigado, por lo que sólo la tragedia, no puede ser de otra manera para que sea costumbre valida, enseñanza propia y definitiva, es "nuestra manera de abandonar dulcemente y para siempre el reino de los vivos y que no seamos consumidos por las llamas que no supimos apagar". Parece que Hölderlin es consciente de lo que le espera. Un riesgo ante el que será prudente para no perder la cabeza. La mayoría piensa que la perdió. Otros que no. Lo cierto es que para Hölderlin, en ese momento crucial tras su viaje a Francia, ya no sirve ni la verdad pronunciada por los dioses, esa "escisión de lo poético, en cuyo afluente se cobijara la Verdad" (Rodríguez García 1994, p. 62), ni la verdad de los hombres, desvanecido el ideal revolucionario. Ante la imposibilidad de alcanzar la verdad, su vida y su obra se convierten en un hilo truncado. Tenía poco más de treinta años. A partir de esos primeros años de siglo, su vida será un largo crepúsculo a los ojos de sus lectores e intérpretes.

Hölderlin había criticado la utilidad de los saberes tradicionales, había asumido el conflicto entre naturaleza y sociedad, entre deber y ser, entre, como ya hemos indicado, filosofía y poesía. Tales conflictos originaron una nueva forma que le conducirá a lo innombrable y a una vida de extraña normalidad, carente de todo lo extraordinario que debería caracterizar a un gran poeta maldito y que tanto acentuará el romanticismo. Una nueva forma quizás definitivamente mítica antes que poética, quizás ingenua, pero intensamente luminosa cuando aparezca en los llamados poemas de la locura.

\section{II.}

Hasta los primerísimos años del siglo XIX en que el hilo se trunca, la vida de Hölderlin es la vida de un héroe con el que renace el espíritu griego, la de un revolucionario que quiere cambiar el mundo hasta el límite del sacrificio, la 
de un idealista de la libertad, la de un nuevo Empédocles que se entrega con radicalidad trágica a la vida, la de un filósofo que parte de la lectura kantiana para, tras el encuentro con Fichte, abrir en canal la tradición moderna más allá de la construcción categórica y significar un nuevo proyecto que problematice la realidad desde el decir literario. Y, sobre todo, la de Hölderlin — no hay duda - es la vida de un poeta que hace de la poesía principio y fin de sí mismo. Así fue. Escribiera poesía o no. La peripecia singular de quien se ve golpeado por la verdad y sus fracturas y pretende con tesón hacer del golpe palabra, aliento lírico, sean cuales sean las dimensiones del poema. Con todos los problemas que eso implica. Vida de poeta, pero — como señalábamos antes — sin perder de vista el referente filosófico.

Retomemos la tensión y la aparente contradicción: porque en una vida radicalmente poética como la de Hölderlin, a pesar de que, por momentos, como ya hemos apuntado, la dedicación filosófica la viera como una dedicación errónea, lo cierto es que la perspectiva, desde la que observamos el conjunto de su obra y de su vida, plantea que la filosofía funcionó como auténtico refugio. De hecho, en los años de madurez del poeta, años de redacción del Hiperión, entre 1796 y 1798 — se publicó en octubre de 1799, pero lo terminó en casa de los Gontard en 1798 - Hölderlin entendía que más allá del primer amor que representa la poesía, está el hospital de la filosofía en el que curarse de los insospechados tormentos entre el decir y el no decir que esconde la palabra y su sentido poético y al que el poeta se ve abocado desde la primera juventud. Lo expresa tal cual en carta fechada el 12 de noviembre de 1798 que escribe a su fiel amigo Nauffer:

«Ay, el mundo amedrentó mi espíritu desde la primera juventud y sufro por ello. Existe un hospital, ciertamente, donde todo poeta desgraciado como yo puede refugiarse todavía con honor: la filosofía. Pero no puedo abandonar mi primer amor, las esperanzas de mi juventud, y antes preferiría perecer sin mérito que alejarme de la dulce patria de las musas de donde solamente me ha apartado el azar. Si puedes aconsejarme para alcanzar lo más rápidamente lo Verdadero, hazlo.»

(Hölderlin 1990b, p. 68)

No hay duda de que Hölderlin es poeta, lo colosal de sus versos lo evidencian y su deseo lo manifiesta — heraldo del Dios ausente—, pero la poesía, que amedrenta, no es sino un medio para alcanzar un fin y ese fin es lo Verdadero. La carta a Nauffer invita a que nos preguntemos por un camino hacia lo Verdadero que no sea el poético. Acaso el desenlace de los llamados "años oscuros de la locura" no fuera precisamente lo Verdadero. Meras conjeturas, cierto. Pero ¿cómo cambiaría nuestra forma de entender esos años si tuviéramos en consideración que una vida 
de apartamiento, silencio y fulgor en breves textos, para algunos poco más que anodinos, fuera el momento en que el poeta alcanzó lo Verdadero, y no con - $\mathrm{O}$ no sólo- la gran poesía que escribió antes de 1805, la de las Elegías, la de los Himnos? ¿Y si lo Verdadero estuviera en la poesía como tentativa, como atisbo, como apunte, boceto, como una mera posibilidad, irreductible a una forma y a una lectura? Gran parte de la mejor poesía que se escribirá después de Hölderlin así lo atestigua: nace del instante en que la inspiración divina es sustituida por la voluntad de un sujeto situado entre la escisión y la unidad, la parte y el todo, la reflexión y la vida, el discurso y la intuición, el yo y el no-yo. Una peculiar manera de sentir, inédita hasta el momento, que atiende a lo fugaz sabiendo que lo Verdadero es imposible de representar. Lo que implica habitar un mundo siempre inestable, en el que la palabra no tiene rotundidad, en el que la irrenunciable singularidad del poeta viene acompañada de una inevitable melancolía. El poeta es otro, que aspira a representar la verdad pero sabe que sólo hay devenir, insuficiencia, que ese ser de la verdad es indecible para la palabra. Siempre tentativa, sugerencia y ocultamiento. A la vez voluntad y carencia, testimonio y fugacidad, impulso y fractura, ilustración y sombra. Sólo puede haber peregrinaje hacia la verdad, deambular a tientas, sin seguridad, porque toda representación está siempre por venir, también el pasado mítico de los dioses. José Luis Rodríguez García ha dedicado páginas intensas a este acontecimiento:

«Ahora estamos en condiciones de identificar a los poetas que moran en la casa del ser: son las sombras que reiteran la representación del estar siendo que tan sólo puede ser representado como aproximación y ocultamiento de lo indecible — pues no se fotografía el viento. La tragedia que asume la autoconciencia poética deriva del hecho de que el poeta sabe que su pasión por representar la verdad del ser, o, si se quiere, el ser de la verdad, está orientada por una radical insuficiencia — pues el ser de la verdad es el devenir que no se presta a decir alguno. Ya es inútil el anatema platónico: es el poeta mismo quien se autoexilia al asumir la tarea de representar lo indecible, al alcanzar la conciencia de que jamás merecerá otro premio que el de anunciar una representación que está siempre por venir.

$\mathrm{Y}$, sin embargo, lo pretende con incansable empeño. El sufrimiento es su ganancia, el único premio que merece.»

(Rodríguez García 2011, pp. 34-35)

Pero avancemos más en la constatación holderliniana de ese incansable empeño por hallar lo Verdadero, "el ser de la verdad"; una búsqueda que le acarreará sufrimiento como único premio. Avancemos en la tensión que concita, entre 
poesía y filosofía, hacia el desgarro con el lenguaje que le espera mientras escribe "escuchando sólo su voz interior, indiferente a todo lo externo" (Cortés Gabaudan 2015, p. 353). Y volvamos a desandar, no importa; es el único modo de incidir.

\section{III.}

La literatura de Hölderlin, con la luminaria de Hiperión al frente, constata la nostalgia por un orden pasado, una Grecia mítica instalada en la primavera de los tiempos y un Occidente no menos idealizado. Nostalgia que es también deseo, expectativa que representa una aspiración política: las ilusiones de la burguesía revolucionaria que nacía en ese momento. Ilusiones heroicas, sin duda, pero que fracasaron estrepitosamente, tanto por la apropiación napoleónica como por la Alemania fragmentada y semifeudal en que vivía Hölderlin. El ideal revolucionario se desvaneció ante los ojos del poeta. Su amigo Sinclair fue acusado de conspiración y en él cundió el miedo ante el peligro. "YYo no quiero ser jacobino! — gritó, según recogen las actas de la investigación del comisionado de la corte de Wurtemberg para esclarecer los hechos- Yo puedo aparecer ante la vista de mi buen príncipe elector con buena conciencia”. (cit. Id. 345). Pero, además del fracaso histórico que el poeta vive, también fracasan sus ilusiones personales: la revista Iduna, trabajar en la Universidad de Jena, ayudar a Schiller, tener un salario. Y fracasó el amor, imposible, por Susette Gontard, su admirada Diotima. Tal sucesión de acontecimientos despliega una "vida sin perspectiva" que dijo A. W. Schlegel. Su familia lo tratará como a un enfermo trastornado, carne para los médicos de su tiempo. El fracaso se extiende a su alrededor, pero Hölderlin sólo quiere ser poeta, poeta en el todo, en busca de lo Verdadero. Lo relata con emoción Helena Cortés en fragmentos que muestran una prosa plena tanto de entusiasmo como de precisión descriptiva:

«El poeta escribe sin cesar toda la noche y todo el día siguiente, varios días y semanas, en que emborrona papel y reescribe y retoca algunos de los versos tal vez más famosos de la poesía occidental. Porque en esos versos de enigmática hermosura, cuya interpretación no se deja aquilatar fácilmente, plasma su convicción de que, pese al posible fracaso de los ideales, pese a la sangre derramada, pese a lo incierto de cualquier empresa humana, por mucho que los hombres y sus ideas pasen y los héroes acaben siendo pasto del olvido, algo queda siempre y algo sienta hondos cimientos más allá de la guerra heroica y hasta del amor: se trata de la poesía.»

(Id. 353)

Helena Cortés contagia la pasión con la que el poeta se enfrentó al que podría ser su último intento por representar la verdad del ser. Hölderlin seguía convencido 
de que la poesía podía conseguirlo, que la poesía permanece, funda, que la poesía es germen. Lo creía Hölderlin y lo cree su biógrafa, que ha titulado el libro La vida en verso — aunque, tras leerlo, se entiende que esa vida no es toda la vida de Hölderlin, sólo su vida "normalizada". Lo cierto es que las más de cuatrocientas páginas del libro giran en torno al entusiasmo por la poesía, a la vocación más radical y desinteresada. La de Hölderlin es la vida paradigmática de un poeta, con toda su luz y toda su sombra. Pero no es la vida de cualquier poeta, sino la de aquel que hace de la poesía un sentido en el que se ponen en juego la conciencia y el deseo, un poeta que pisa terreno vedado para casi todos. Como escribiera Heidegger: "La poesía de Hölderlin está sustentada por la determinación poética de poetizar la esencia de la poesía. Hölderlin es para nosotros, en un sentido eminente, el poeta del poeta" (Heidegger 55-56).

Decíamos al principio de esta nota que La vida en verso no ofrece una lectura ideológica. Aspecto difícil de lidiar si tenemos en cuenta que la relación HölderlinHeidegger marca la reflexión sobre el poeta y en dicha relación hay un verdadero conflicto: el paso del Documento de Cultura a Documento de Barbarie, como bien han señalado Philippe Lacoue-Labarthe o José Luis Rodríguez García (2013). Aquí no vamos a abundar en esta discusión, simplemente remitimos a los autores referidos.

Ustedes podrán decir respecto del binomio Hölderlin-Heidegger que no estamos sólo ante un problema político-ideológico sino que también, o más bien, ante un asunto de estética ontológica que conduce a la sacralización de la poesía como nexo con la verdad. Podemos recordar las palabras de Octavio Paz con las que colocaba a Hölderlin como uno de los limos de los que nace la poesía contemporánea: "La palabra poética es mediación entre lo sagrado y los hombres y así es el verdadero fundamento de la comunidad. Poesía e historia, lenguaje y sociedad, la poesía como punto de intersección entre el poder divino y la libertad humana, el poeta como guardián de la palabra que nos preserva del caos original: todas estas oposiciones anticipan los temas centrales de la poesía moderna." (Paz 66-67). Lugar central el de la poesía, pero es inevitable la alusión política y uno, desde luego, no la puede esquinar. Sin embargo, no es el caso del libro que nos ocupa, La vida en verso, en el que la centralidad está en la poesía y en el poeta que busca, que media, que preserva.

«El poeta no echa raíces, no construye casas, no funda hogar ni familia, el poeta peregrina eternamente en la noche de la ausencia de dioses, pero es el que transporta consigo el licor que puede aliviar a lo que tienen sed poética, es el sacerdote de una religión que ya no cree en los dioses celestes ni en los templos de mármol, sino en 
la belleza de la primavera. Porque, además, y se ha visto que lo sagrado no puede dejarse en manos de los sacerdotes y las iglesias, y mucho menos del Estado y los políticos, pues del Estado y de la Iglesia sólo cabe esperar constricción, ideas predeterminadas, distintas formas de asfixia de lo único que hace soportable la precariedad de la vida, de lo único que deja huella trascendental y funda para la eternidad: el arte. Por eso, la misión del poeta es heroica y sagrada.»

(Cortés Gabaudan 2015, p. 328)

Misión en busca de la verdad de lo real y del arte - sea transcendente o inmanente - suponiendo que eso sea posible. Para Cortés Gabaudan es el fundamento de la vida de Hölderlin y, por lo tanto, el de su libro. De ahí que se lo dedique a todos los poetas, a quienes buscan la verdad con tal empeño que incluso arriesgan la vida o el juicio al convertirlo en algo sagrado, mágico en tanto que originario, esencial. Camino por el que sólo deambularían extraños al mundo cotidiano, héroes trágicos: Hölderlin, paradigmático ejemplo, pero también Leopardi, Keats, Rimbaud, Ezra Pound o Antonin Artaud; héroes que escribieron en el agua o callaron ante un mundo innombrable. El destino, parece decirnos Helena Cortés, que mueve la peripecia de los poetas - los citados y cualquiera - es la verdad poética, acaso distinta, aunque sea extraño, paradójico de entrada, dividir la verdad en unas u otras. Y ese destino poético siempre impulsará a los poetas a un eterno retorno de lo mismo — "Érase una vez un poeta..." finaliza Helena Cortés su libro (Id. 432)_, inscrito en un tiempo que no es kerónos o tiempo ordinario, sucesivo en su movimiento, físico, sino kairós, tempus latino que comparte etimología con tempestas o temperamento, tiempo plegado sobre sí mismo, capaz de ver el futuro en el pasado y emancipar el presente suspendiéndolo en esperanza revolucionaria (agradezco la idea a Jesús Ezquerra). ¿Qué es si no Hiperión? Pero como dijo Gadamer, otro lector de Hölderlin, hablar es buscar la palabra y encontrarla es siempre una limitación (Gadamer 62). Hölderlin buscó la verdad poética pero acaso, y aquí es donde no entra Helena Cortés, no quiso limitarse y se exilió en la fractura de las formas que había cultivado, en constatar la imposibilidad de hallar la verdad, en el silencio de una vida cualquiera. Blanchot fue revelador al respecto escribiendo sobre Mallarmé; una argumentación que, disculpen, sirve en su planteamiento igualmente para Hölderlin:

«La palabra poética no se opone entonces solo al lenguaje ordinario, sino también al lenguaje del pensamiento. En esta palabra ya no somos remitidos al mundo, ni al mundo como abrigo, ni al mundo como fines. En ella el mundo retrocede y los fines desaparecen, en ella el mundo se calla; finalmente, lo que habla no son ya los seres en sus preocupaciones, sus propósitos, su actividad. En la palabra poética se 
expresa lo que los seres callan. ¿Pero cómo ocurre esto? Los seres se callan, pero entonces el ser tiende a convertirse en palabra y la palabra quiere ser. La palabra ya no es palabra de una persona: en ella nadie habla y lo que habla no es nadie»

(Blanchot 35)

El destino de Hölderlin será palabra poética como búsqueda de la verdad en tanto que él mismo se convierta en nadie. Palabra poética opuesta tanto al lenguaje ordinario como al de la filosofía. Hölderlin espera ser nadie, al menos ser otro, inadvertido respecto a quien era.

\section{IV.}

Jacobo Muñoz en un reciente libro, El ocaso de la mirada burguesa, donde reflexiona sobre Hölderlin y la nostalgia, alude a Sartre para explicar la enorme decepción en que terminó sumido el poeta: Sartre definió al hombre

«-que ha llegado incluso a ser caracterizado como una retícula de deseos e intereses sin centro fijo- como un ser cuya esencia consiste en negar precisamente lo que es, esto es, como un ser que no es lo que es y es lo que no es. Un ser que está a la espera, pues. Que alienta expectativas. Y que acaba, en consecuencia, por conocer la decepción. [...] Fundamentalmente, los que en algún momento o, incluso, como programa vital soñaron 'serlo todo'»

(Muñoz 30)

¿Acaso no guardaba Hölderlin — como cualquier otro ser humano, aunque él más que ninguno, pues ha sido uno de los pocos que soñó serlo todo- en su ser aquello que era pero no era?: negó la ausencia de poesía para terminar siendo eso, ausencia de cualquier esperanza en la poesía. "La palabra ya no es palabra de una persona: en ella nadie habla y lo que haba no es de nadie" que escribía Blanchot. La desesperanza, la decepción a la que alude Sartre, se desató cuando Hölderlin, tras las demoledoras experiencias vividas, terminó sumido en la enorme decepción de no conseguir armonizar a los hombres con lo divino, de ver cómo, aunque "lo que permanecen lo fundan los poetas" que escribe tras su viaje a Burdeos, las palabras son incapaces de suturar el mundo humano que deambula en paralelo a la naturaleza. Los sueños devienen delirio. Las piezas de la totalidad se agrietan y no hay lenguaje que lo arregle.

«Ciertamente — escribe Helena Cortés—, Hölderlin parece haber perdido o haber querido perder el lenguaje. Si ya en Hiperión se anteponía el canto de Diotima o el puro silencio de la naturaleza a cualquier otra forma de expresión, porque «el 
lenguaje es un auténtico y superfluo desperdicio. Lo mejor queda siempre para sí mismo y yace en sus honduras como la perla en el fondo del man», en sus últimos poemas lúcidos el poeta ofrece indicios que apuntan en la dirección hacia una despedida consciente de la poesía y del lenguaje humano como forma válida de expresión $[\ldots] »$

"Un signo somos, sin interpretación;

sin dolor somos, y casi perdimos

el lenguaje en lo ajeno.”

(Esbozo de poema “Mnemosyne", 1800/01)

[...] El exilio interior al que emigra el poeta en la segunda mitad de su vida coincide con esta percepción desgarradora de la imposibilidad del lenguaje.»

(Cortés Gabaudan 2015, pp. 370-371)

Porque, como ha desarrollado José Luis Rodríguez García (quien escribiera un libro fundamental para la bibliografía holderliniana, Friedrich Hölderlin: El exiliado en la tierra), lo más probable es que no haya un vínculo necesario entre naturaleza humana y arte, es decir poesía, pues "el arte bien pudiera no haber aparecido en nuestras sociedades y que, por lo mismo, dada su contingencia, podría disolverse sin que nos viéramos afectados por cataclismo alguno (Rodríguez García 2015, p. 123).

Si ni siquiera el lenguaje permanece y la poesía es mera contingencia, sólo queda la melancolía. Hölderlin se autoconsiderá ajeno a su tiempo, ajeno a sí mismo, ajeno a lo que había sido hasta ese momento. Así lo escribe en uno de sus más memorables poemas de la locura:

«Lo agradable de este mundo ya lo he gozado, las horas juveniles mucho ha que volaron, abril y mayo y julio quedan ya muy lejos

Yo ya nada soy, yo vivir ya no quiero.»

(Lo agradable de este mundo, en Cortes Gabaudan 2015, p. 368)

Ya sólo puede ser "exiliado en la tierra". El yo Hölderlin sujeto de una historia deja de ser quien es. No quiere. Carece de voluntad por ser el poeta que le significaba. El relato de esa biografía se fractura. La respuesta a ¿Quién es Hölderlin? a partir de las fuentes y los documentos, a partir de la palabra, se concluye. El destino poético deja de constituirse en lo que era y se establece con nuevas coordenadas: sentido hacia adentro, como verdadera vida, pero vida que ya no es del Hölderlin que hemos conocido, sino de un otro; lo abierto se ocluye. Otro de los poemas de la locura señala el camino: 
«Otorgado en su interior es a los hombres el sentido,

Hacia lo mejor él ha de guiarlos,

Esa es la meta, la verdadera vida,

Ante la cual más espiritualmente los años van contando.

Scardanelli»

(Humanidad más elevada en Hölderlin 1978, p.59)

La búsqueda sigue siendo para Hölderlin la de lo Verdadero. Pero quien enuncia ya no es él sino Scardanelli. Otro. Para el biografiado Hölderlin, la verdadera vida era la naturaleza, la totalidad spinoziana explicable mediante una "nueva religión de la Razón" que es también práctica moral. El destino para quien tiene una vida en verso era nombrar esa totalidad con poesía, porque la palabra poética permanece pese a la intemperie. La poesía era una práctica moral. Incluso, para ese personaje de la historia, la filosofía, el refugio que acompaña, debería ser también poética, expresarse como una sola. Y sobre todo, refugio. Pero, para Scardanelli —otro entre otros-, la meta de lo verdadero está en el interior. Y de ese interior no hay documentos posibles. No hay posibilidad de contar la historia. No hay relato. No podemos hacer hermenéutica. No hay qué interpretar, salvo testimonios de quienes episódicamente visitan al enfermo, como Waiblinger, y sancionan al llamado Hölderlin como loco, anormal, extravagante, diferente de quien era. "Exiliado en la tierra". El destino del poeta era el de un peregrino, que buscando lo Verdadero en la poesía se perdió. Nosotros reconocemos esa pérdida, ese extravío de la razón que sancionamos comúnmente como patológico. Hölderlin dejó de ser racional, abandonó la práctica poética y filosófica con vocación de universalidad: no sabía cómo continuar y su costumbre viró de forma radical, se exilió de quien era. José Luis Rodríguez García profundizó en este asunto en El exiliado en la tierra. En el primer "exergo" del primer volumen de su estudio sitúa el problema:

«Ser racional es pensar el problema. Toda moral no derivada de los principios éticos sustentados en la universalidad que presta una disciplina dictadora es inútil, no es saber, o, mejor dicho, es la proclamación de un no-saber que insulta.»

(Rodríguez García 1987, p. 84)

Y la moral de Hölderlin se descuelga de principios éticos dictados como universales. Lo que no puede sino provocar desconcierto, pues, quien actúa de acuerdo con una búsqueda radical en su particularidad, no sabe ser como los demás ni como sí mismo en tanto que igual a los demás. Y ese es el destino del poeta: "un no-saber que insulta”. Poco más adelante, continúa Rodríguez García: 
«Hölderlin rompe con la exigencia de las preguntas obligatorias aunque no acierte a saber el motivo último de su conflictividad; es su relato el de los sentimientos, el de las vivencias existenciales. (...) Pero, entonces, ¿qué suerte ha de correr el sujeto náufrago en un espacio de plurales y enfrentadas subjetividades —esto es, códigos morales? [... ] Y, dada la naturalidad de las mismas y de sus consecuencias, ¿qué destino aguarda? ¿Qué futuro...? [...] sueña un espacio social, histórico y político de convivencia de racionalidades diversas sin que la diferencia devenga en necesidad de la lucha.»

Sólo queda sueño, expectativa, anhelo. Nada más. La suerte del sujeto náufrago es la de quien deja de ser sujeto de una historia literaria, personaje de una aventura extraordinaria, espejo y brújula de la autenticidad, para convertirse en un loco más, un anónimo carente de destino poético, otro de los cualquieras que habitamos el mundo. Hölderlin se vio ante las puertas del bien y del mal y tuvo que elegir cuál era el camino de la verdad, que diría el viejo Parménides. Y ese dejó de ser el camino del gran poeta que sabe, para convertirse en alguien que no sabe, para el que el lenguaje no es suficiente. Capaz todavía de descolocarnos y cuestionar el estatuto de verdad y normalidad, Hölderlin inició un viaje hacia el fondo de sí mismo tras un conocimiento que ya no coincidía con el destino poético con el que tantos de sus lectores aún disfrutamos. Nosotros recorremos la biografía y vemos ese destino interrumpido, carente de verso a partir de un momento dado, de un verso espectacular, rotundo, que abra más y más preguntas, más o menos prohibidas. Para muchos, cuando eso desaparece, Hölderlin deja de tener sentido. No obstante, para el propio Hölderlin, lo que había dejado de tener sentido era, precisamente, el poeta que era.

Hölderlin nunca había sido un poeta más pero llegó a dejar de ser cualquier poeta: "feliz a su medida, aislado, se supone loco antiguo, castigado por haber rozado el límite de una manía arrebatadora, por haber traído al tiempo preguntas prohibidas" (Id. 333)

Páginas inmensas del Hiperión ya anunciaron la incertidumbre:

«Todo ha acabado, Diótima. Nuestras gentes han saqueado y asesinado sin hacer distingos. También nuestros hermanos, los griegos de Misistra, inocentes, han muerto o huyen desesperados, y su expresión de miseria y muerte clama venganza a cielos y tierra contras los bárbaros a cuya cabeza estaba yo.

¡Ahora puedo ir por ahí y predicar mi buena causa! ¡Sí, ahora volarán hacia mí todos los corazones! 
¡Aunque también yo me he comportado de forma muy inteligente! Ya conocía a mis hombres. De hecho, era un proyecto extraordinario pretender fundar mi Elíseo con una banda de ladrones.

¡No, por la sagrada Némesis! Me ha pasado lo que tenía que pasarme, y debo soportarlo y lo soportaré hasta que el dolor me arranque el último resto de consciencia.

¿Crees que deliro? He recibido de uno de mis leales una honrosa herida cuando traté de oponerme a la matanza. Si delirara, arrancaría la venda que le cubre y mi sangre fluiría a donde debe, a esta tierra fúnebre.

¡Tierra fúnebre y desnuda que yo quería vestir con bosques sagrados, que quería adornar con todas las flores de la vida griega!

¡Ah, qué hermoso hubiera sido, Diótima!

$¿$ Crees que he perdido el valor? ¡Querida mí, son demasiadas desgracias juntas! Surgen por todas partes bandas sanguinarias; como una epidemia, se propaga el pillaje por la Morea, y el que no empuña la espada es acosado y degollado, iy estas furias dicen que luchan por nuestra libertad! ¡Y el resto de este pueblo salvaje, que está al servicio del sultán, se comporta igual que ellos!

No sé qué será de nosotros. El destino me lanza a lo desconocido y me lo merezco; de ti me destierra mi propia vergüenza, iy quién sabe por cuánto tiempo!»

(Hölderlin, 1986, pp. 158-159)

Después de tanta peripecia, "El destino me lanza a lo desconocido y me lo merezco" escribe Hölderlin. La verdadera vida pasará a tener sentido "otorgado en su interior" escribirá Scardanelli. Para Hölderlin sólo hay incertidumbre. La incertidumbre que le espera a cualquiera. El destino de nadie. Leemos en la "canción al destino que en los días felices y no apreciados de la juventud había aprendido de mi amigo Adamas":

«Pero a nosotros no nos es dado

descansar en ninguna parte;

desaparecen, sufren

los hombres, caen

ciegamente de una

hora en otra, como agua, de roca

en roca arrojada

durante años a la incertidumbre.»

(Ib. 190) 
Desde la incertidumbre hasta la completa disolución de lo que era. Lo Verdadero ha tornado en poco más que silencio. Hölderlin alcanza su destino poético en la más violenta de las salidas: el apartamiento consciente del mundo, la enfermedad, la locura. Ser nadie. Al resto nos queda entregarnos a la lectura de sus textos, los propiamente holderlinanos, inconmensurables y siempre por leer, y los que presentan a otro poeta. Ambos requieren una lectura radical, que nos arroje a lo que nosotros somos también: incertidumbre y esperanza, libertad y realidad, amor, sobre todo amor, necesidad de amor que escribió el gran Joan Vinyoli.

«Habiendo leído las poesías de Hölderlin, lo primero que sentís, si os proponéis reflexionar un poco sobre su secreto, es que han nacido de una absoluta necesidad. (...) Otra realidad hecha sólo de presentimientos y deseos y añoranza de otro mundo que el nuestro es lo que vive en la poesía de Hölderlin. Y es que la motivación de esta poesía es aquel anhelo profundo, inexplicable que hay en el hombre de eternidad y que llamamos amor.»

(Vinyoli 63).

\section{V.}

La vida de Hölderlin es el elogio de la melancolía de un gran solitario que busca fatalmente amor, fraternidad en un archipiélago de piezas, entonces y ahora, y como lectores nos encontramos ante tal dilema: vemos tanto la armonía de una poesía lírica que se dirige a los dioses y nos impulsa a mirar a lo abierto como las hora indecisas que significan la pérdida de abrigo, el continuo errar iguales a las sombras, la ausencia de lenguaje, la radical diferencia. Aquí, a lo largo de estas líneas, no nos hemos detenido en el comentario de los poemas ni en el recorrido que la poesía propicia en sus detalles, sino en otros aspectos, pero concluyamos con la mirada puesta en ella, en alguno de los poemas que despuntan más intensidad, pues es por donde Helena Cortés en todo momento conduce su excelente biografía. Y lo hace, como hemos dicho al inicio, con entusiasmo admirable. Leamos algún fragmento de las grandes elegías del poeta del Neckar, escritas, como sus odas y sus himnos, en el segundo semestre de 1800, posiblemente el periodo creativo de Hölderlin más extraordinario, plena madurez poética, cima de su genio antes de la decepción por todo, porque en las elegías se recoge aquello que señaló Manuel Ballestero en El principio romántico: la subjetividad subversiva que "tiene un su interior un movimiento doble: de rebeldía y de capitulación, de irrupción crítica y de aceptación no consciente de lo que está impugnando". (Ballestero 99). Nos señala uno de los conflictos que subyacen: el ser o no consciente. Y junto a él, —en él—, recuerdos y esperanzas, 
aproximación y ocultamiento de y con las palabras, el intento de representar lo indecible. Sólo así es posible poetizar lo real nos dice Hölderlin. Y estar en lo abierto como lo Verdadero; pensar con juicio y ser jovial. Intentarlo con la mayor esperanza. También con compromiso político. Revolucionario. Y el amor del que hablara Vinyoli mientras, en paralelo, avanza inevitable la oscuridad. Hölderlin lo escribe en "El paseo campestre" o en "Pan y vino":

«Ven a lo abierto, amigo, aunque sea poca luz la que desciende hoy y el cielo nos encierre en la angostura.

Ni las cimas más altas del bosque ni los montes se han podido expandir como quisiéramos y el aire está parado y vacío de cantos. Hoy el día es gris, duermen las callejuelas y caminos y casi me parece que de nuevo estuviéramos en una edad del plomo.

En cambio, desear nos está permitido, pues quien piensa con juicio no vacila por una hora tan sólo y el día sigue aún consagrado a la alegría.»

(“El paseo campestre", Hölderlin 2009, p. 87)

«Pero el error ayuda. Y la noche y el sueño y la aflicción pueden fortalecernos hasta el día en que vuelva a haber héroes suficientes que, criados en cunas de hierro, guarden tanto rigor en su pecho, que puedan emular a aquellos celestiales.

Envueltos por los truenos, yo sé que ellos vendrán, pero, mientras espero a que llegue esa hora, Algunas veces preferiría dormir a hallarme como estoy: sin compañeros, Aguardando, expectante; pues ¿qué hacer entretanto?

¿Qué decir? No lo sé... ¿y para qué poetas en tiempos miserables?

Mas ellos son — tú dices_ igual que aquellos sacros celebrantes del dios de los viñedos

que vagaban de una tierra a otra por la noche sagrada.»

("Pan y vino", Id. 119)

No puede decirse mejor en apenas unos versos. Ahí radica la potencia y la actualidad de Hölderlin: la rebeldía y la capitulación. Mientras haya un lector de Hölderlin, esperaremos los nuevos héroes, nos entregaremos una y otra vez al dios Dionisio. Y no por ello dejaremos de cuestionar la excepcionalidad de lo poético. La poesía como intersección entre la verdad y la posibilidad de que esa verdad sea dicha. La poesía frente el caos de la realidad: una salvación que es siempre tentativa, apenas contorno pero suficiente. En el poema de 1798 dedicado a las parcas y que Helena Cortés traduce, Hölderlin no deja lugar a la duda sobre su destino poético: 
«Concederme, oh Poderosas, sólo un verano, un otoño en que pueda madurar mi canto, para que con tan dulce juego ya saciado, mi corazón acceda a morir de buen grado.

El alma que nada divino obtuvo en vida tampoco ya en el Orco encontrará reposo, mas si una solo vez lo sagrado yo aún logro, lo que más quiero en este mundo, la poesía, entonces, sombras, yo os daré la bienvenida, y contento estaré, aun si dejo abandonada bajando al silencio mi lira. Un solo día habré vivido como un dios y eso basta.»

(en Cortés Gabaudán 2015, p. 321)

La poesía que iguala a dioses y poetas. Vivir poco más, pero ser capaz de escribir poesía que sea verdad, que diga lo indecible. Que ésa sea la auténtica salvación. Luego, ya sabemos, esa salvación se convertirá tanto en memoria de lo que nunca ha sido como en esperanza de un porvenir que será siempre proyecto, diseminación constante que implicará una tensión límite, hilo truncado, consciente renuncia. Pero Helena Cortés Gabaudán decanta su biografía por la celebración de la poesía, en ella Hölderlin sigue madurando su canto, ese día al que podemos volver una y otra vez y en el que el poeta vive como un dios. Un dios exiliado.

Hölderlin, exiliado siempre, como hemos visto, a la búsqueda del tiempo de la verdad hasta desgajarse incluso de quien era, pero también inscrito radicalmente en sus poemas. Y, obvio, en cada una de las lecturas en las que tantos y tantos nos detenemos una y otra vez desde hace más de doscientos años buscando el luminoso incendio de las posibilidades. Lectores colosales, como muchos de los que hemos ido citando a lo largo de estas líneas, y lectores anónimos, cualquieras, que hacen — que hacemos_ de lo poético una singularidad al margen tanto de lo sagrado como de lo mundano.

“Y para qué poetas en tiempos miserables?" se preguntaba Hölderlin en "Pan y vino". Con todas las cautelas que impone la contingencia de lo poético, no podemos olvidar que la respuesta de Hölderlin era el anhelo de una sociedad mejor, más justa y libre. La poesía como fundamento de cualquier comunidad. Con cautelas, hemos dicho. Y además, podemos añadir las lecturas de se derivan no sólo de ese primer Hölderlin sino también del que no quiere ser Hölderlin: la diferencia que se articula entre el orden intelectual y el intuitivo y que a partir del 
amor, como decía Vinyoli, nos permite mirar, no sin decepción y melancolía, de un lado a lo abierto y de otro al interior de nosotros mismos.

\author{
David Mayor Orgillés \\ Colegio San Alberto Margno (Zaragoza) \\ dmayorgilles@gmail.com
}

\title{
BIBLIOGRAFÍA CITADA
}

BAlLestero, M. (1990): El principio romántico, Barcelona: Anthropos.

BERTAUX, P. (1983): Hölderlin ou Le temps d'un poete, Paris : Gallimard.

Blanchot, M. (1992): El espacio literario (trad. V. Palant y J. Jinkis), $2^{\mathrm{a}}$ ed., Barcelona: Paidós.

Cortés Gabaudan, H. (1996): Claves para una lectura de Hiperión. Filosofía, política, ética y estética en Hölderlin, Madrid: Hiperión.

- (2015) La vida en verso. Biografía poética de Friedrich Hölderlin, Madrid: Hiperión.

Gadamer, H. (1999): Poema y diálogo (trad. D. Najmías y J. Navarro), Barcelona: Gedisa

HärTling, P. (1986): Hölderlin. Una novela (trad. Th. Kauf), Barcelona: Montesinos.

HeidegGer, M. (1983): Interpretaciones sobre la poesía de Hölderlin (trad. J. M. Valverde), Barcelona: Ariel.

HÖLderlin, F. (1978) Poemas de la locura precedidos de algunos testimonios de sus contemporáneos sobre los "años oscuros" del poeta (trad. Tx. Santoro y J. Ma Alvárez), Madrid: Peralta.

- (1986): Hiperión (trad. J. Munárriz), $8^{a}$ ed., Madrid: Hiperión.

(1990a): Correspondencia completa (trad. H. Cortés Gabaudan y A. Leyte), Madrid: Hiperión.

(1990b): Cartas (trad. J. L. Rodríguez García), Madrid: Tecnos.

(2009): Las Elegías (trad. J. A. García Román), Barcelona: DVD.

- (2015): Antología. Versiones y probaturas de Joan Vinyoli (eds. T. Christ y A. Ferrer), Madrid:

Visor.

JASPERS, K. (2001). Genio artístico y locura (trad. A. Kovacsics), Barcelona: Acantilado.

Muñoz, J. (2015): El ocaso de la mirada burguesa. De Goethe a Beckett, Madrid: Biblioteca Nueva.

Lacoue-Labarthe, Ph. (2007): Heidegger. La política del poema (trad. J. F. Megías Flórez), Madrid: Trotta.

PAU, A. (2008): Hölderlin. El rayo envuelto en canción, Madrid: Trotta.

PAZ, O. (1990): Los hijos del limo, $3^{\mathrm{a}}$ ed., Barcelona: Seix Barral.

Rodríguez GarcíA, J. L. (1987): Friedrich Hölderlin: El exiliado en la tierra, Zaragoza:

Prensas Universitarias de Zaragoza.

- (1994): Verdad y escritura. Hölderlin, Poe, Artaud, Bataille, Benjamin, Blanchot, Barcelona:

Anthropos. 
RoDríguez GARCíA, J. L. (2011): El hilo truncado, Zaragoza: Eclipsados.

- (2013): «Sobre la apoteosis de la Barbarie », en J. L. Rodríguez García y L. Beltrán Almería (coords.), Cultura o barbarie, Zaragoza: Mira, pp. 53-87.

(2015): "Poesía, sociedad y nosotros", en AA. VV, Poesía y filosofía, Madrid: Calambur, pp. 123-177.

VALero, V. (2015): El arte de la fuga, Cáceres: Periférica.

VINYOLI, J. (2015): "El secreto de Hölderlin”, en F. Hölderlin, Antología. Versiones y probaturas de Joan Vinyoli, Madrid: Visor.

WeIss, P. (1996): Hölderlin, Pablo Sorozabal Serrano (trad.), Hondarribia: Hiru.

Zambrano, M. (1996). Filosofía y poesía, México D.F.: Fondo de Cultura Económica, 4ª ed. 